\title{
Two Kinds of Victims: Meeting Their Needs
}

Ruth Morris

Gor some years I have included in my standard lectures on penal 1 abolition or creative alternatives, a section on victims and their needs. I culled this from the standard literature on victim needs. When I first read it, I was astounded to see that revenge was not generally found to be a primary need of victims. The five primary needs all victims share are as follows.

\section{Answers:}

All victims instinctively want answers to a whole variety of questions, including the universal "WHY ME"? Although this is in part a spiritual question, it is one which the particular offender can partially answer, assuring the victim that they were not picked on deliberately (if that is the case). Most other questions can only be answered by the offender in the case:

- why did you smash the basement window?

- Can you return my ID which is of no value to you but a lot to me?

Many of these questions seem trivial or frivolous, but they can obsess victims. The reason is logical when we think about it. The nature of being a victim is that one's life space is invaded, and the power to control one's little area of safety is violated. Getting answers to these questions helps victims to regain a sense of understanding, essential to regaining a sense of control and safety.

Howard Zehr has said that victims have to "retell their stories of violation to friendly ears until they have reconstructed their understanding of who they are with this tragedy included in it." Getting answers from offenders helps victims do that.

\section{Recognition of their Wrong.}

Probably the most powerful need of victims is to have their wrong recognized as a significant wrong, not something they brought on themselves, or something trivial to be passed over lightly. Of course courts do just the opposite: much of the court process, especially any defence mustered for the accused, shows the victim to be somehow at fault, weak, neglectful, provocative, or otherwise contributing to their victimhood. The layers on layers of incomprehensible process in which the victim is trivialized and ignored do not convey recognition of their 
wrong. Often victims are not even informed of any arrest in their case if they are not needed to testify.

Our society recognizes wrongs very unevenly, at best. Being born poor or black or indigenous and thus experiencing systemic discrimination all one's life is not considered a wrong to be recognized. Workplace wrongs tend to be blamed on their victims: anyone complaining of their last employer in job interviews is not likely to be hired. On the other hand rape, which used to be blamed on the victim, has recently, thanks to the work of the feminist movement, become recognized as a very significant wrong for which victims are not to be blamed.

\section{Safety.}

A renewed sense of safety is an obvious victim need, yet the court process often fails to provide this. The alienation between offender and victim is widened, which increases fear and anger on both sides. The only real security could be found in a protective, supportive community, but instead our system makes a bogey-man of even mild, nonviolent offenders, and puts victims as well as offenders at the mercy of a powerful "justice system" whose arbitrary processes and decisions provide safety to neither victims nor offenders.

\section{Restitution.}

Restitution is a widely recognized, but often misunderstood victim need. Courts recognize it by making erratically chosen restitution orders. Many crimes are committed in an effort to pay an unrealistic restitution order, which the offender cannot meet. About 60 percent of court-set restitution orders are not paid, not only because many are impossible, but also because since neither victim nor offender are included in setting it, the offender does not feel committed to an order which makes no sense to her/him, and is just another part of a name-calling burdensome system that hates and rejects her/him.

What we mean by restitution is something else: restitution is about restoring to the victim a sense of a community that cares about them. Thus there CAN be restitution even in rape and murder cases, for restitution is not about tit for tat; restitution is about restoring community. When Hurricane Carter called to the front of the first Association in Defence of the Wrongfully Convicted Conference, seven people who had served 160 years for crimes they had nothing to do with, that audience 
gave each of those people a standing ovation. Tears ran down a lot of faces as Hurricane Carter hugged each one in front of that cheering, applauding, deeply moved audience. Nothing can give those people back the decades spent in prison, the parents whose deathbeds they missed, the children they never saw grow up, but that community tribute was restitution: it was a powerful declaration of community by people who cared deeply about what they had gone through. THAT is restitution.

\section{Significance, or Meaning.}

The last need of victims is in some ways the most beautiful: victims of any kind need to find significance in what they have experienced. We will never have answers to all the big questions in this world: no one else will recognize our wrongs as deeply as we feel them; we never feel quite as safe after a violation of our space; and, restitution of community still cannot give us back what we have lost. Sooner or later mature victims on the healing path realize they have gotten as much of the first four needs met as they are going to get. They cannot turn back the clock and make it unhappen. But, they can resolve to use what happened to them to make the world a better place, a safer place, for someone else, and even prevent someone else suffering what they did.

Thus, a mother whose child drowns in a public pool launches a move for better lifeguard protections. Terry Fox started a run to conquer cancer that still fires the imagination of Canadians. A woman whose bus driver husband was shot by youths in a low income part of an American city launched a fund to provide better recreation for youths in that neighbourhood. Mothers whose children have been killed by drunk drivers have launched a movement that has changed public attitudes toward drinking and driving (MADD).

\section{Two KINDS OF VICTIMS}

The examples given in the preceding section are of victims of all kinds of situations: crimes, accidents, diseases, and systemic injustices. In fact, any trauma that comes unwanted, takes away our power over our own life, and brings us pain, makes us feel a victim. But we will eliminate from further discussion here what are commonly called "Acts of God" (although many believe this title maligns the Divine unnecessarily). The kinds of trauma which we have no way to prevent: cancer, hurricanes, 
tidal waves, aneurisms, will not be considered further here. But, this still leaves TWO kinds of victims:

1. Victims of DISTRIBUTIVE INJUSTICE

2. Victims of STREET CRIME

Our corporate dominated media, in their efforts to divert our attention from the overwhelming reality of corporate crime and corporate exploitation, usually define "victim" as a victim of street crime. Yet, the larger number of victims by far are victims of distributive injustice. UNICEF statistics indicate that 40,000 children die each day, 17 million per year, from lack of necessities or exhaustion - surely THIS is a justice issue! Yet our justice system never addresses such questions.

The UN Development Report of 1992 stated that in 1990 the richest 20 percent of the world's population had 60 times the income of the poorest 20 percent (Goudzwaard \& deLange, 1995. pp. 13-14). Distributive or structural injustice victimizes through: higher infant mortality, shorter lifespans, less educational opportunities, poorer housing and nutrition, worse health and health care, less access to jobs, and greater exposure to all kinds of violent risks. Yet we seldom hear the word victim applied to victims of distributive injustice: marginalized people and groups.

So in considering victims, we need to ask WHICH kinds of victims do we mean - victims of distributive injustice, or victims of street crime.

\section{The POOR ARE Victimized By Both}

Marxist and other social justice analysts harp on victims of distributive injustice, while advocates of the retributive justice system and upholders of the status quo dwell on victims of street crime. Neither group considers that we do not have to choose sides: BOTH are true victimizations, and BOTH are more often visited on the poor and marginalized than on any other group. Both deserve our support, and both have the five victim needs discussed above.

But whereas racism, classism, and sexism harm victims of distributive injustice, street criminals victimize those hurt by street crime. Ironically, most prisoners are major victims of BOTH kinds. Racial minorities and poor people fill prisons everywhere, and the system from start to finish sifts in the marginalized and sifts out the elite. But it is also true that prisoners are probably more often victims of street crimes than 
most other groups: many have experienced gang beatings, muggings, rapes and other sexual violence, family violence, police beatings and even torture, theft, extortion - you name it, they are consumers as well as perpetrators of victimization.

This means that poor people and prisoners should be supported in meeting their five healthy victim needs, as defined above. It also means that we do not have to choose between kinds of victims - a healthier society can respond to the healthy victim needs of victims of distributive injustice AND of street crime. Moreover only the newer transformative justice approaches which bring victim, offender, and their communities together, empowering them to find a solution that meets their needs, can respond to the five victim needs effectively. Native healing circles and family group conferences are the best known of these, but some victim offender processes that include community can meet the five victim needs fully as well.

\section{FREEING VictiMS}

We are a "penaholic" society, and the powers that be, in their coverup of the corporate thieves that are destroying our economy, our environment, and our civilization, encourage victims of street crimes to remain stuck in a revenge mentality. But despite this, many victims and some victim groups see through the trap, and find peace through healing, transformative processes. Wilma Derkson's work with the Mennonites in Canada is one example, but the USA has a number of groups working to this end.

Perhaps the most remarkable is a group called MURDER VICTIMS FAMILIES FOR RECONCILIATION. They put out a newsletter, do talks, and frequently organize major walks across large parts of the country. Every one of them has lost a loved one to a brutal murder. Far from holding onto bitterness, their stories all follow the same theme. Many of them, failing to get their healthy needs met in our society, did start down the bitter revenge path. But at some point they realized they were stuck. Often some traumatic moment changed their awareness, but sometimes it was just the emptiness and despair of the revenge path, which was eating them up.

Bill Pelke's story is typical of these remarkable folk. His wonderful Christian grandmother was knifed to death in her own home by a gang of teenage girls bent on robbery. Bill and his Dad attend the trial of Paula, 
the 15 year-old leader of the gang, and wanted the death penalty. But when it came, Paula's grandmother in the courtroom burst into loud sobs. Suddenly Bill saw in his mind's eye a painting of his Grandmother they had - and he saw that she was crying. He knew his Grandmother would not want a murder to succeed her murder.

From that moment Bill led the fight to get Paula off death row. American media would not cover it at first, so he took his cause to Europe, and the Italian media feted him, from which the American media picked the story up. Not only did Bill succeed in getting Paula off death row, but today they correspond, and there is a video showing Paula commenting with wonder on this human being who actually wants to meet and help her. She says words to this effect, "I don't understand how he can want to meet me. I don't understand him at all. But all I know is this: if there had been a Bill Pelke in my life, before this happened, I don't think any of it would have happened at all."

Victims come in all sizes, colours and conditions. We are all victims at some point in our lives. This world is a lonely place unless we learn to support each other in meeting those core needs of all victims: finding answers, recognizing their wrongs, gaining safety, obtaining restitution, and creating meaning out of their personal tragedies. Prisoners, like all of us, are both victims and victimizers. But victims like Bill Pelke are showing us that we can transcend victimhood, and create significance out of any tragedy - and the greater the tragedy, the greater the potential significance.

\section{REFERENCES}

Goudzwaard, and deLange (1995). Beyond Poverty and Affluence. Toronto:University of Ottawa Press.

Morris, R. (1995). Penal Abolition: The Practical Choice. Toronto:Canadian Scholars Press. 